Em entrevista, $a$ presidente da SBPJOR, Cláudia Lago, destaca o atual cenário da pesquisa em Jornalismo no Brasil, no âmbito político e científico, critica a falta de mais estudos sobre gênero e étnico-raciais, aborda a internacionalização e a cultura de pesquisas em rede para o campo.

Por: Janara Nicoletti e William Robson Cordeiro (doutorandos do POSJOR/ UFSC)

Estudos em Jornalismo e Mídia Vol. 13 No 2 Julho a Dezembro de 2016 ISSNe 1984-6924

\section{Silêncios, potencialidades e desafios da pesquisa em Jornalismo}

Questões de gênero e étnico-raciais são pouco exploradas nas pesquisas em Jornalismo e apresentam um grande potencial para o campo, defende Cláudia Lago, a presidente, em sua segunda gestão, da Associação Brasileira de Pesquisadores em Jornalismo (SBPJOR). A problemática que foi tema de abertura do $14^{\circ}$ Encontro Nacional de Pesquisadores em Jornalismo, em novembro de 2016, também é debatida nesta entrevista. A presidente da entidade ainda comenta sobre os rumos da pesquisa em Jornalismo no Brasil, a necessidade de se buscar um novo olhar para os estudos no campo e os impactos das reformas políticas federais para a ciência e a educação.

Formada em Comunicação Social - Jornalismo, na Faculdade de Comunicação Social Cásper Líbero, em 1989, Cláudia Lago é mestre em Antropologia Social pela Universidade Federal de Santa Catarina e doutora em Ciências da Comunicação pela Universidade de São Paulo (USP). Atualmente, debruça-se sobre as pesquisas com foco na construção da alteridade, em especial, de gênero.

Em um recente levantamento realizado pela SBPJOR, a diretoria observou a baixa produção de estudos com esta temática no campo do Jornalismo. Condição que pode ser analisada como reflexo da cobertura noticiosa em nível mundial. "Enquanto os profissionais jornalistas, homens e mulheres, não se atentarem para as questões de gênero e étnico-raciais, isso não vai aparecer na cobertura. E a cobertura jornalística é um horror neste ponto de vista”, analisa a presidente da SBPJOR, que observa esta ausência como uma potencialidade para a pesquisa no campo.

Segundo ela, aos poucos, estudantes de graduação e pós-graduação despertam para essas questões e contribuem para dar visibilidade a grupos "esquecidos" pela cobertura noticiosa de grandes grupos e, por muito tempo, também marginalizados no campo científico.

Nesta entrevista para a EJM, concedida durante o $14^{\circ}$ Encontro Nacional de Pesquisadores em Jornalismo (SBPJOR 2016), em Palhoça (SC), a professora da Escola de Comunicações e Artes da USP também citou outras ausências presentes na área científica, como a necessidade de se ampliar a produção de estudos empíricos e o isolamento acadêmico, o que dificulta a troca de conhecimento entre pesquisadores. Para ela, apesar de existirem diversas redes dentro da própria SBPJOR, ainda é preciso incentivar uma cultura de pesquisa em rede.

Cláudia Lago defende a internacionalização dos estudos brasileiros, com a ampliação de publicações em inglês, para que os trabalhos produzidos no Brasil tenham maior visibilidade no exterior. Além disso, enfatiza o esforço de reconhecimento do jornalismo como uma área de conhecimento e a importância da integração com outras áreas, em um modelo interdisciplinar. "Particularmente, acredito em pesquisas coletivas e pesquisas interdisciplinares. $\mathrm{O}$ jornalismo tem muito a contribuir com isso e a ganhar. Até para entender o fenômeno do jornalismo", observa.

Confira a entrevista na íntegra a seguir: 
EJM - Professora, em sua palestra na abertura da SBPJOR 2016, em Palhoça (SC), um tema central de sua abordagem foram os silêncios do jornalismo e as questões de gênero. Poderia retomar um pouco do que foi colocado?

CLÁUDIA LAGO Já faz um certo tempo que eu trabalho, que gosto e venho me debruçando para estas pesquisas que envolvem mapeamento, de perceber o que as pessoas estão fazendo, de que forma as pessoas estão fazendo e os temas de interes-

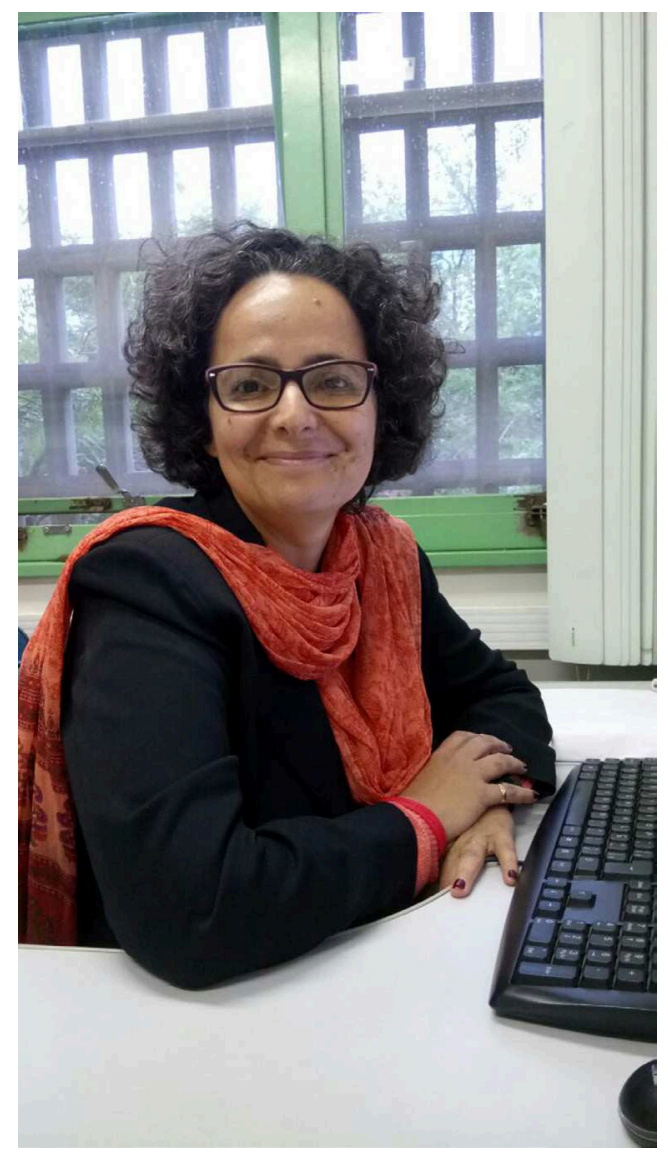

mencione, porém nenhum se organiza em torno desta reflexão. Mas, não é apenas o recorte de gênero. Trabalhos que pensam a questão étnico-racial também são absolutamente ausentes.

EJM - Acredita que isso é um reflexo ou se reflete na cobertura noticiosa?

CLÁUDIA LAGO

- Eu acho que a cobertura noticiosa, que não é só um problema do Brasil e sim mundial, se reflete no campo profissional e no se. Desde que eu assumi a presidência da SBPJOR, da primeira gestão (2013-2015) - este é o meu segundo mandato -, tenho tentado olhar um pouco para a nossa base de dados, que é rica em termos de pesquisa em Jornalismo no Brasil. Daí, fizemos vários mapeamentos, como o de 2013 e desde então percebemos estes silêncios. Percebemos que havia temas que eram tão importantes para a sociedade, que surgiam no tecido social, mas não se refletiam na produção da pesquisa sobre jornalismo. E continuamos este trabalho e, com um pouco mais de intensidade, confirmamos estas ausências de temas e abordagens por parte dos pesquisadores. Isso é algo extremamente contraditório. São vários os silêncios. Aqueles que me chamam a atenção, por serem o meu objeto de trabalho atualmente, são os estudos que têm o recorte de gênero. É muito gritante isso que ocorre na base de dados da SBPJOR - seja na área que reúne todos os congressos, quanto no levantamento que fizemos nas comunicações coordenadas em 2014 e 2015. É impressionante como não existem trabalhos que têm como ponto principal este tema. Pode até ser que um trabalho ou outro campo reflexivo da pesquisa. Isso não deveria acontecer. É óbvio que, enquanto os profissionais jornalistas, homens e mulheres, não se atentarem para as questões de gênero e étnico-raciais, isso não vai aparecer na cobertura. E a cobertura jornalística é um horror neste ponto de vista. Vou dar um exemplo para vocês, que me deixou chocada. Eu dou aula de pós-graduação e a minha disciplina é $\mathrm{Al}$ teridade, Diversidade e Gênero e tem um recorte para pensar as narrativas não-ficcionais onde eu enquadro o jornalismo. Tenho algumas alunas ouvintes, graduandas em jornalismo que participam de coletivos feministas, que me contaram que nas redações existe uma orientação quando for entrevistar mulher ou homem. Se for entrevistar homem, chame pelo sobrenome, mas a mulher chame pelo nome. Tem uma lógica maluca para tentar mostrar isso que nem elas conseguiram me explicar. Fiquei aturdida: "Gente, não acredito que eles falam isso nas redações". Não sei se é fofoca, mas não duvido. A ONU, desde a conferência de Pequim, mapeia, a cada cinco anos, o tratamento que a imprensa dá às mulheres, algo bem mais amplo. As respostas 
são muito óbvias e muito complicadas ainda, mesmo com as mudanças dos últimos anos na América Latina. Vamos pensar por vários ângulos: as básicas como as ocupações dos postos de chefia, os salários... Mas, minha preocupação é com a representação, como isso se dá. Isso tem aparecido também nestes levantamentos internacionais.

\section{EJM - O jornalismo ainda é muito ma- chista?}

CLÁUDIA LAGO - O jornalismo é absolutamente machista e é horroroso. Não importa o que a gente considera como bom ou mau jornalismo. Ele é horroroso neste sentido. Por exemplo: mulheres são entrevistadas para quê? Para assuntos da ordem do privado. As grandes fontes sempre são homens. Quando se vai fazer uma entrevista e precisa que alguém fale sobre economia, se procura um homem, não uma mulher. Não importa se uma mulher entenda de economia: "Imagina, uma mulher falar de economia!" O mesmo ocorre com a política. Quem são as suas fontes? A gente começa por aí e é naturalizado que seja assim. Já vi professores dizerem: "Se ele é a fonte, por que procurar ela?” Mas, por que ele é a fonte? "Ah, porque ele tem expertise". Por que ele tem expertise? Será que não precisamos jogar outras formas de ver, de narrar, de pensar as coisas? Porque é natural que seja assim. O problema é que, enquanto não fizermos estudos sobre isso, a gente não desnaturaliza e a gente vai continuar fazendo as coisas porque sempre foi assim.

EJM - Retomando o seu ponto de vista inicial sobre as ausências. A questão metodológica também é percebida?

CLÁUDIA LAGO - Em meus levantamentos, não tenho me atido sobre uma avaliação metodológica dos trabalhos. Pesquisadores têm feito esta discussão não só no jornalismo (neste caso, o professor Elias Machado tem uma pesquisa intensa sobre isso), mas no campo da Comunicação. É muito interessante observar como nos nossos trabalhos há problemas do ponto de vista metodoló- gico por não entender este fator como algo essencial. Mas há exceções e recentemente participei de uma banca de doutorado em que a construção metodológica foi muito pensada. A metodologia está a serviço do objeto. Uma pesquisa que eu e a Cláudia Nonato fizemos na base de dados, apresentada na Alaic - Associação Latino-americana de Investigadores em Comunicação, apontou que muitos de nossos trabalhos têm uma característica ensaística. Ora, não há problema em se fazer um ensaio, mas significa que a gente não está fazendo pesquisa empírica. Não estou querendo diminuir o ensaio, mas isso não pode ser majoritário.

\section{EJM - Como o que ocorre com a pes- quisa aplicada?}

CLÁUDIA LAGO - Claro. Falta preocupação com a pesquisa aplicada. Temos notado isso há muito tempo, inclusive na SBPJOR deste ano. No Seminário de Pesquisa de Pós-Graduação em Jornalismo, o tema foi a pesquisa aplicada. E isso tem tudo a ver com os mestrados que estão surgindo, a base dos mestrados profissionais. Existe uma preocupação sim, mas esta preocupação não aparece na produção reflexiva do campo.

\section{EJM - E por qual razão?}

CLÁUdIA LAGO - Eu precisaria pensar um pouco para ter uma hipótese a respeito disso, mas acho que tem mais a ver com a questão cultural que acaba influenciando no perfil dos cursos. Eu acho que está muito mais entranhada na cultura de pesquisa, para o que e para que lado a gente olha.

EJM - Um tema discutido no último congresso da SBPJOR e também levantado na palestra de abertura foi sobre as potencialidades do jornalismo. De que maneira poderíamos falar sobre um tema tão amplo?

CLÁUDIA LAGO - Tudo na vida é amplo e complexo, não é? Não podemos ser reducionistas, nem olhar o mundo a partir de nossas ideologias, mas olhar para esta complexidade. Por isso, precisamos trabalhar coletivamente, porque assim 
eu tenho um olhar e meu colega tem outro e o outro tem outro e assim vai... No fim, a gente consegue ter uma realidade multifacetada para poder pensar. $\mathrm{O}$ trabalho coletivo é fundamental por isso. $\mathrm{E}$ o trabalho individual em pesquisa é um horror também; digo, só o pesquisador naquele seu caminhozinho a vida inteira, etc... É o que acaba sendo incentivado por nossos sistemas de pesquisa. Apesar de afirmarem que precisam de pesquisas coletivas, a lógica é toda voltada para a pesquisa individual. Mas, do ponto de vista das potencialidades, a primeira coisa que temos de fazer é olhar para fora sem achar que o mundo está acabando (como algumas pessoas veem), sair um pouco de nossas bolhas e olhar o que está acontecendo. O que eu vejo de potencialidade? Fico olhando para a garotada da graduação, por exemplo, e vejo a quantidade de meninas envolvidas em coletivos feministas. Vejo uma quantidade de meninos preocupados com isso e apoiando. Isso, para mim, é potencialidade. Vejo estudantes extremamente críticos nestes lugares, alunos negros criticando o deslocamento negro na sociedade brasileira. E as alunas negras também, que trazem um outro olhar, que trazem ainda a questão do feminismo, da classe e da raça. São impactantes do ponto de vista das potencialidades porque estas pessoas estão produzindo narrativas também e estão colocando estas narrativas na rua. Uma série de blogs, sites, espaços de produção de narrativas, que não são mainstream, mas que estão fazendo coisas muito boas e questionando muito esse mundo na forma como está sendo contado. Além disso, dentro do mainstream você tem ilhas e brechas, gente fazendo coisas muito interessantes. Às vezes, não percebemos devido à avalanche de conteúdo, do status quo, que nem notamos e paramos de ler o jornal. Todo mundo lembra da Eliane Brum, mas não é só ela. Ela é excelente, tem uns textos pensando a questão da diversidade muito legais. No entanto, há muita gente boa fazendo muita coisa interessante a duras penas. As estruturas ainda são muito coercitivas, de fazer todo mundo pensar den- tro da caixinha, mas tem gente fazendo muita coisa boa. "Ah, são coisas que não impactam tanto quanto a Globo..." Ok, gente, mas vamos cair na real. Não vamos conseguir ter uma anti-Rede Globo do outro lado. O que a gente tem de fazer é abrir possibilidade de ter leituras diferentes do mundo nesta cena. E é isso que estas pessoas estão tentando fazer.

\section{EJM - A pesquisa em jornalismo preci- sa acompanhar estes movimentos?}

CLÁUDIA LAGO - Precisa acompanhar e dar visibilidade a estes movimentos. $\mathrm{O}$ que uma pesquisa faz? As pessoas acham que pesquisa é aquela coisa que as ajudam a compreender o mundo. A pesquisa tem um papel de mudança do mundo, porque ela ajuda a dar visibilidade. Um exemplo simples: o documentário "Menino 23". Foi uma tese de doutorado da Unicamp sobre meninos negros escravizados, no interior de São Paulo, por família rica e nazista. Esse trabalho virou um documentário, concorrendo a prêmio. É um exemplo muito linear, básico, não é toda pesquisa que faz isso. Mas, as pesquisas dão visibilidade para as questões e temas que passam como se fossem coisas dadas que são assim porque são assim. As pesquisas nos dão armas para lutar contra determinadas naturalizações perversas. Por isso, precisamos de boas pesquisas, fundamentadas metodologicamente, que não defendam somente "a minha opinião".

EJM - Como a SBPJOR está vendo as redes de pesquisadores dentro do campo do jornalismo? Há um esforço para formar estas redes?

CLÁUDIA LAGO - Esta é uma questão interessante. A SBPJOR não tem GT. Tem uma estrutura diferente, que não é engessada. Há dois tipos de apresentação de trabalhos: em comunicações livres ou comunicações coordenadas. Na primeira, se faz o texto, apresenta e nós, da SBPJOR, vamos determinar quais os demais textos que irão acompanhá-lo. A segunda é diferente: as pessoas se organizam antes, fazem textos que têm uma ementa, que dialogam entre si e fazem uma pro- 
posta de mesa. Só que, com o tempo, as pessoas começaram a apresentar essas mesas em vários congressos seguidos e a ter discussões mais consolidadas, abrindo para a ideia das redes. A SBPJOR acolheu desde o início e discutiu como seria esta rede de pesquisa. Como isso está hoje? As redes não são o problema. O problema está na nossa cultura de trabalho quanto à pesquisa coletiva. Não temos incentivo para fazer pesquisa coletiva. Todos os principais editais são para o pesquisador e as pesquisas coletivas demandam um certo tipo de relação que muitos ainda não conseguem ter. Nós temos várias redes e uma série de regras e requisitos para se formar uma, mas sentimos que elas ainda estão engatinhando na formação real de uma pesquisa em rede. Por enquanto, muitas apresentam temas conjuntos, exploram esses temas, mas são lentas na proposição coletiva em que todos sentam para pesquisar a mesma coisa dentro de um guarda-chuva. É um processo lento, mas realmente elas estão empenhadas. Com o tempo, acredito que vamos construir esta cultura. E neste sentido a SBPJOR é muito importante em colaborar com as redes e estimular as pesquisas coletivas.

EJM - E a relação dos pesquisadores de jornalismo no Brasil com outros do exterior e, especialmente, na América Latina?

CLÁUDIA LAGO - Ainda tem a ver com essa cultura das pesquisas individuais. Os pesquisadores agem sozinhos e divulgam suas pesquisas sozinhos lá fora. Dificilmente se faz isso enquanto um esforço coletivo. Até porque há pesquisadores que gastam do próprio dinheiro para ir a um congresso internacional e apresentar sua pesquisa, o que dificulta quando falamos de algo mais orgânico. A SBPJOR tem tentado estimular que esta divulgação internacional das nossas pesquisas, que os contatos dos pesquisadores realizados individualmente no exterior, revertam em benefício para o conjunto da entidade. É complicado porque depende também do perfil das pessoas envolvidas. Algumas se preocupam com isso, outras não.

\section{EJM - O Brasil não está isolado quanto a isso?}

CLÁUDIA LAGO - Não, o Brasil não está isolado. Mas não se conhece tanta gente lá fora, nem tantos pesquisadores estrangeiros vêm para cá. O fato de a SBPJOR se esforçar em trazer nomes para o Brasil e colocar os pesquisadores de fora em contato com as nossas pesquisas tem sido importante. A revista BJR [Brazilian Journalism Research] tem um papel fundamental nisso. Vou dar um exemplo de como isso funciona. A professora Beatriz Becker fez um pós-doc com o professor James Caron, na Inglaterra, e será lançado um livro de suas pesquisas. O James Caron fez uma apresentação do livro e ela estava me contando toda satisfeita. $\mathrm{O}$ James Caron veio para o nosso congresso de 2015 e ficou impressionado com o Brasil e com a SBPJOR. Na apresentação, ele elogia muito a Bia e o seu esforço de internacionalização e se dispõe a fazer uma série de coisas que muitos pesquisadores não se dispõem. E além de elogiar o esforço, diz que ela não está sozinha, que existe uma entidade como a SBPJOR que também está se esforçando. Ela ficou felicíssima e eu fiquei mais ainda, porque a entidade tem o papel de tentar transformar essas culturas. E a internacionalização tem de ser feita por todos.

EJM - Institucionalmente, a SBPJOR tenta estabelecer parcerias com entidades internacionais?

CLÁUDIA LAGO - Não só tenta, como faz. A gente já está lançando o JRE online (estamos fechando o ISSN), uma publicação que é uma parceria entre a SBPJOR e a Journalism Research and Education, da IAMCR [International Association for Media and Communication Resear$c h$ ], e que será anual, ligado aos temas da JRE feito a partir de uma miscelânea de pesquisadores de ambas as entidades. Estamos desenhando como deve funcionar esse trabalho. A JRE online não tem a preocupação da BJR - em que queremos classificá-la, colocá-la no Scielo, no Scopus, obter o Qualis A2 para começar, 
enfim... A JRE é um veículo de contato de pesquisadores do mundo e nós achamos que é muito importante que o Brasil articule, porque temos muito mais facilidade de fazer essas articulações dos que os demais pesquisadores do mundo. A gente tem essa coisa de que nós estamos abertos para o mundo e, em outros lugares, as pessoas têm mais dificuldade, embora propensas. Vai ser muito legal essa parceria e que seja uma vitrine do que os pesquisadores estão fazendo no mundo. Esta é uma parceria que espero que continue ad eternum. Estamos pensando em outras também.

\section{EJM - E as perspectivas para a pesquisa diante dessas mudanças de governo e a crise?}

CLÁUDIA LAGO - Eu participo da reunião da SBPC como representante da SBPJOR há muito tempo. E não lembro de nenhuma reunião em que não se tenha falado em cortes. Na pesquisa, faz anos que isso acontece. Enquanto este país, e digo enquanto sociedade brasileira, não entender que pesquisa e educação são essenciais, não vai mudar. Eu acho que as coisas agora estão muito piores, porque agora as pessoas não têm compromisso nenhum com isso. Para que algo seja feito ou não tem muito a ver com as relações de força, com o compromisso. E isso não estou sentindo. Não compromisso com saúde e educação. Não deveria propor um corte por 20 anos na saúde e na educação. Deveria ser pensada uma reestruturação com cortes em outras áreas se possível, a fim de aplicar em saúde e educação. A lógica deles é diferente e, no meu ponto de vista, completamente maluca. A gente não sabe ao certo o que vai acontecer porque tudo depende deste jogo de forças em que nós estamos implicados. E cabe a nós, enquanto comunidade científica, se articular e começar a brigar muito. É preciso que saiamos de nossas bolhas acadêmicas e coloquemos para a sociedade esta questão. Para nós, é um consenso que precisamos de mais verba. Mas, será que a sociedade acha isso também? A gente precisa mostrar para a sociedade que é preciso. A gente vive num país muito conservador, elitista, em que as pessoas não precisam ser da elite para considerar as lógicas da elite corretas. Por isso, precisamos sair da bolha e mostrar que não é assim que a coisa funciona.

\section{EJM - A SBPJOR tem acompanhando} a transição dos cursos de Jornalismo diante das novas Diretrizes Curriculares?

CLÁUDIA LAGO - A SBPJOR, especificamente, não tem acompanhado, porque estamos com muitas demandas referente às pesquisas e à pós-graduação. Nós temos uma entidade irmã, o Fórum que agora é a Associação Brasileira de Professores de Jornalismo que tem essa preocupação e expertise. Com a professora Sônia Virginia Moreira, vice-presidente da SBPJOR, eu fiz um trabalho em que analisamos alguns novos currículos. Percebemos que os currículos estão sendo implantados. Até que ponto vai mudar, fica em aberto. Educação é uma aposta de longo prazo. Muda-se algo agora para ter efeito daqui a cinco, dez anos. Por isso, as descontinuidades da educação são tão perniciosas. Então, não tem muito o que a gente perceber agora. Uma vez eu vi no Facebook alguém revoltado com a cobertura jornalística e ela disse: "Isso é culpa dos currículos de jornalismo, estes novos jornalistas que estão sendo formados com essas novas diretrizes". Mas, eu pensei: "Ainda não tem nenhum jornalista formado a partir das novas diretrizes e muito menos atuando na imprensa”. As diretrizes são importantes e fundamentais. É preciso entender isso. Nas universidades públicas, que gozam de autonomia, é menos importante que nas universidades privadas. Eu era de uma universidade privada e se ela não tiver diretriz, faz-se qualquer coisa, algo absurdo. Por isso, acho que essas discussões das diretrizes sempre foram muito descontextualizadas, porque quem brigava muito era o pessoal das universidades públicas. Só que $80 \%$ dos estudantes brasileiros são formados em universidades privadas. E essa é uma outra discussão também, não é? Conti- 
nuamos na nossa bolha da autonomia universitária. Não existe autonomia universitária fora da universidade pública. $\mathrm{E}$ se não tem diretriz, sai debaixo. $\mathrm{O}$ que for mais barato, mais fácil e mais simples, é o que vai acontecer. Por isso, as diretrizes são importantes para organizar isso minimamente. Até que ponto isso vai ser colocado e funcionar vai depender de vários fatores, inclusive de uma avaliação constante das universidades privadas. Não adianta só as diretrizes se na prática o ensino é de péssima qualidade. Não estou dizendo que o ensino na universidade privada é ruim. Não, depende muito. Temos exemplos de cursos maravilhosos. O que eu quero dizer é que precisamos olhar um pouco mais ao nosso redor, em vez de ficar partindo de uma discussão que é feita dentro de certas condições, não olhando para o lado. Se as diretrizes vão redundar em melhoria, eu espero que sim. Agora vai depender, como eu disse, das correlações de forças.

EJM - Algumas entidades da área de Comunicação foram contrárias às Diretrizes. Como isso se deu e de que maneira respingou na pesquisa?

CLÁUDIA LAGO - Na época, houve uma série de discussões. Mas, no meu entender, há sempre certa confusão sobre o que é um curso de profissionalização e a pesquisa. A pesquisa não precisa estar atrelada ao curso de profissionalização. Mas é preciso ter regras para a profissionalização, que precisam ser acordadas com quem está envolvido.

EJM - Como a senhora vê a necessidade do jornalismo se envolver com outras disciplinas, como por exemplo, com profissionais da área de tecnologia para desenvolvimento de produtos e de formatos?

CLÁUDIA LAGO - Eu acho muito importante que o jornalismo trabalhe a partir de um modelo interdisciplinar. Mas, que tenhamos consciência que nós temos a expertise num determinado campo e que não precisamos nos sentir diminuídos ao dividir esta expertise com outros campos. Particularmente, acredito em pesquisas coletivas e pesquisas interdisciplinares. O jornalismo tem muito a contribuir com isso e a ganhar. Até para entender o fenômeno do jornalismo.

EJM - Para concluir, o jornalismo é um campo de pesquisa que está sendo marginalizado diante de outras áreas?

Acho que não. Não sei se a palavra "marginalizado" dá conta. As Ciências Humanas e Sociais e Sociais Aplicadas, no corpo geral das ciências, são extremamente desprestigiadas em relação às Ciências Biomédicas e as Exatas. Essa é uma lógica social que não acontece apenas no Brasil, é mundial, mas aqui tem contornos muito complicados. A SBPJOR tem trabalhado muito com o Fórum Nacional das Ciências Humanas, Sociais e Sociais Aplicadas, que reúne entidades de todas essas áreas. Nós temos discutido como nos organizar para, coletivamente, conseguir contrapor a esse trator das outras áreas que são prestigiadas sempre em detrimento da gente. São muitas coisas, uma longa discussão de detalhes e problemas. O mais recente e risível deles foi a tentativa de obrigar as Ciências $\mathrm{Hu}$ manas, Sociais e Sociais Aplicadas a se organizarem quanto à ética estabelecida pela Plataforma Brasil, que é uma ética feita para as Biomédicas - que tem lógica de pesquisa completamente diferente da nossa. Na Biomédica, se alguém vai ser objeto da pesquisa, ela pode ser submetida a um remédio que pode implicar em risco. Assim, é necessária uma série de cuidados que são diferentes de uma pesquisa do jornalismo, em que eu entrevisto alguém. Muito sinteticamente, o Fórum nasceu por causa disso e, a partir daí, está discutindo outras coisas como, por exemplo, ter uma grande área nossa, com diretoria no CNPq. 